\section{O ECLIPSE DE 1919 E A TEORIA DA RELATIVIDADE: RUMO A ILHA dO PRÍNCIPE}

Ana Simões

INTRODUÇÃO O eclipse solar total de 29 de maio de 1919 foi observado por quatro equipes de expedicionários - duas britânicas, uma brasileira e outra norte-americana. Das equipes britânicas, uma conduziu o astrofísico Arthur Stanley Eddington (1882-1944) e o especialista em mecanismos de relojoaria Edwin Turner Cottingham (1869-1940) à Ilha do Príncipe, então colônia portuguesa, na costa oeste africana; a outra levou os astrônomos do Observatório de Greenwich, Andrew C.C. Crommelin (1865-1939) e Charles Rundle Davidson (1875-1970), a Sobral, no estado do Ceará, nordeste brasileiro, onde se juntaram às equipes brasileira e norte-americana para observar o fenômeno.

Contrariamente às expediçōes brasileira e norte-americana, que tinham objetivos tradicionais, tendo realizado observaçôes de astrofísica e de magnetismo terrestre, respectivamente, as equipes britânicas tinham um objetivo singular: testar a recente teoria da gravitação (teoria da relatividade geral) de Albert Einstein (1879-1955) e, em particular, a previsão do encurvamento dos raios luminosos que passam junto de grandes massas gravitacionais, com um valor estimado de desvio de 1,75" segundos de arco.

O encontro improvável entre Einstein e Eddington, assim como os motivos que levaram o astrônomo real britânico Frank Watson Dyson (1868-1939), conjuntamente com Eddington, a tentar organizar as comitivas, incluíram ingredientes muito diferentes dos habituais [1], conferindo contornos multifacetados à preparação e execução das expedições num tempo político particularmente adverso associado à Primeira Guerra Mundial e aos contextos diversos, nacionais e coloniais, dos locais de chegada.

Tal como era tradição no contexto da astronomia, redes de contactos entre comunidades de astrônomos foram acionadas para que as equipes expedicionárias recebessem dos países de acolhimento, isto é, do Brasil e de Portugal, todo o apoio necessário, por via das suas instituições e personalidades científicas. Em Portugal, num primeiro momento foi contatada a Sociedade de Geografia de Lisboa, solicitando-se um mapa e informações meteorológicas da Ilha do Príncipe e, num segundo momento, iniciado a 11 de novembro de 1918, o dia em que o armistício foi assinado, sucedeu-se uma troca mais extensa de correspondência entre Eddington e o sub-director do Observatório Astronômico de Lisboa, coronel Frederico Thomaz Oom (1869-1930), com vista à marcação das viagens e acomodação na Ilha do Príncipe.

Para além dos objetivos estritamente científicos, as expedições e as viagens que as integram cruzam sempre ciência e poder, economia

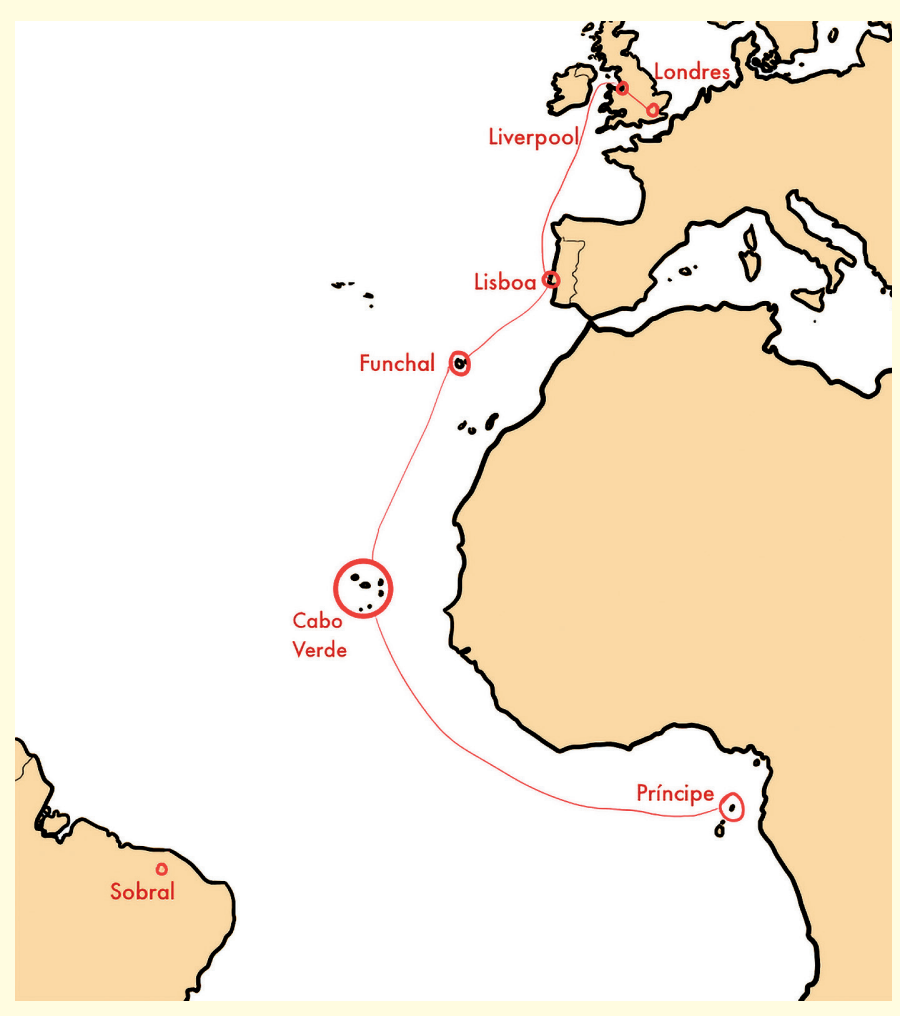

Figura 1. 0 trajeto dos expedicionários rumo à Ilha do Príncipe Crédito: Duarte Crawford

e política [2]; deslocam pessoas, instrumentos e objetos, em movimentos dominados por peripécias e contratempos inesperados; e, apesar do cuidado cirúrgico posto na sua preparação, estão sempre sujeitas a incertezas que testam a tenacidade dos expedicionários mais teimosos.

As expedições organizadas para observar o eclipse solar total de 29 de maio de 1919 não fugiram à regra. No que concerne às expedições britânicas, envolveram dois anos de preparativos em tempo de guerra, que culminaram em cinco minutos de observações sujeitas às partidas do tempo meteorológico. Apesar do apoio financeiro do governo britânico, não houve direito a novos equipamentos e o rigor das medições dependeu de instrumentos construídos ou adaptados de partes pré-existentes, dispersas por vários observatórios britânicos e recolhidas no Observatório Real de Greenwich para os preparativos finais. Foram deslocadas cerca de duas toneladas de material para cada comitiva, para regióes tropicais junto ao equador, situadas a distâncias de pouco mais de $7200 \mathrm{~km}$, no caso do Sobral, e de $5800 \mathrm{~km}$, no caso da Ilha do Príncipe. E, finalmente, o seu sucesso dependeu da participação de astrônomos do Brasil e Portugal, de membros das elites locais, mas também de trabalhadores e serviçais que ficaram para sempre anônimos.

Para além das comunicações e publicações científicas, alguns dos astrônomos britânicos em trânsito, e muito em particular 


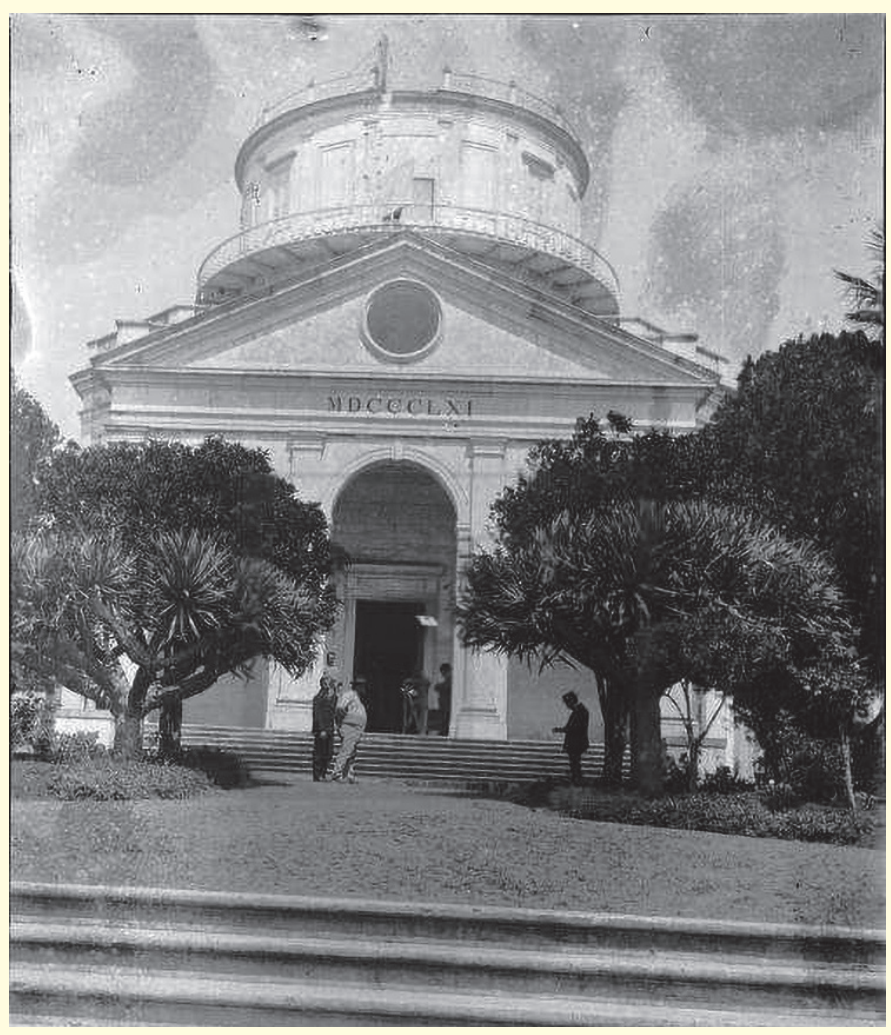

Eddington, produziram comentários e até relatos mais ou menos circunstanciados das peripécias associadas às viagens que os levaram a lugares tão longínquos e exóticos. Os relatos de Eddington são o objeto deste artigo. Produzidos por um astrônomo experiente e exímio comunicador, oferecem ao leitor um olhar sobre paisagens, locais, pessoas e experiências alheios à rotina diária do seu autor.

DE LIVERPOOL AO FUNCHAL, COM PASSAGEM POR LISBOA Depois de dois anos de negociaçóes e longos meses de preparativos, culminando nos trabalhos finais de adaptação de instrumentos e construção do material, na véspera da partida os expedicionários deslocaram-se de Greenwich para Liverpool, trazendo consigo o equipamento. Saíram do porto de Liverpool rumo a Lisboa, no vapor Anselm, no dia 8 de março.

As impressões do vapor foram muito positivas. Maior e mais confortável que as expectativas, com cerca de 60 passageiros de primeira classe a bordo, as cabines partilhadas dois a dois, uma por Eddington e Cottingham e a outra por Davidson e Crommelin, estavam bem colocadas a uma altura apreciável do nível do mar. Apesar das boas condiçôes gerais da viagem, a passagem pelo Golfo de Biscaia foi turbulenta [3].

A vida a bordo refletia alguns dos constrangimentos do tempo de guerra, apesar do armistício já ter sido assinado: os passageiros não podiam ser informados nem da localização nem da rota. Mas, para além disso, tudo se passava como se os tempos fossem de normalida-

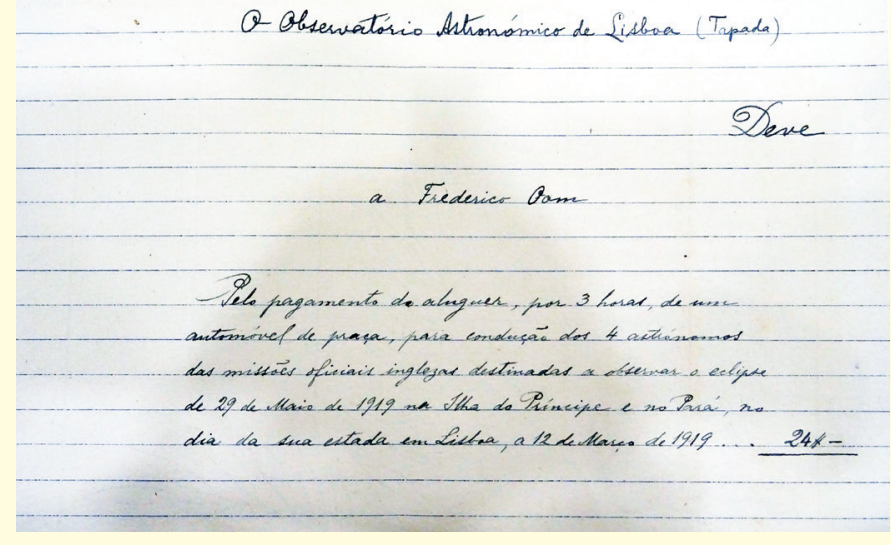

Figura 2a. Observatório Astronômico de Lisboa. Crédito: Arquivo Nacional Torre do Tombo, PT/TT/EPJS/SF/008/09595 Figura 2b: Bilhete de Frederico 0om. Crédito: Arquivo MUHNAC/OAL

de, muito especialmente no que dizia respeito à diversidade, qualidade e quantidade dos alimentos, em que abundavam açúcar, carne, pão branco e pudins. A sociabilidade era a típica das embarcações de longo curso e incluía refeições com o capitão, jogos e conversas entre os passageiros de várias nacionalidades, entre os quais se encontrava um astrônomo amador britânico que ia missionar na Amazônia.

A chegada em Lisboa ocorreu no dia 12. Frederico Oom esperava-os. Visitaram o Observatório Astronômico de Lisboa durante cerca de duas horas, conheceram o diretor César Augusto Campos Rodrigues (1836-1919), um velho charmoso (de 82 anos) que não aparentava ser um vice-almirante [4], e admiraram a Tapada da Ajuda em que o observatório se localizava, com as amendoeiras em flor. A viagem até o observatório e o regresso ao barco foram feitos num carro que Oom alugou por três horas com o propósito de lhes mostrar um pouco de Lisboa e, em particular, da zona de Belém [5]. Ao contrário das impressões de 1912, em que Eddington referia que Lisboa não parecia uma capital europeia, mas antes um entreposto comercial, em jeito de grande mercado [6], agora Eddington notava apenas que Lisboa parecia muito pacífica, ainda que cheia de soldados e sem polícia à vista.

A verdade é que, a todas as incertezas e contratempos de uma viagem planejada em plena Grande Guerra, acrescia-se também a situação política de uma enorme instabilidade por que Portugal passava desde finais de 1917. Tratou-se do processo que conduziu Sidónio Pais, em maio de 1918, à presidência da República que ele acumulou com o cargo de primeiro ministro. Foi um período acompanhado por modificações impostas à matriz republicana que vigorara até então e que conferiram ao mandato de Pais um cunho presidencialista e ditatorial que culminou no seu assassinato, em 14 de dezembro de 1918. Em carta a Oom, datada de 4 de fevereiro de 1918, Eddington 
escrevia: "Verificamos que todas as viagens de barco para Lisboa estão presentemente canceladas — suponho que devido à revolução. Confiamos que o senhor e o Observatório se encontram ilesos." Referia-se naturalmente à instauração da junta revolucionária de 1917 por Sidónio Pais. Afinal, foi possível parar em Lisboa e não admira, pois, que se espantasse com a calmaria presenciada.

É de notar que na correspondência trocada, e apesar dessa menção à revolução, Oom nunca fez quaisquer comentários relativos à situação política nacional. É claro que o dever de ajuda científica aos astrônomos expedicionários fazia parte da sua ética enquanto homem de ciência. Sempre o tinha afirmado e praticado. Assim fizera quando preparou, com minúcia e profissionalismo, a recepção às equipes de astrônomos estrangeiros que se deslocaram a Portugal para observar o eclipse de 1900, visto na totalidade no país [7]. A esse sentido de missão acrescia, muito possivelmente, a crença na disjunção entre as esferas científica e política, ainda que na prática Oom pugnasse por afirmar o Observatório como uma instituição republicana, empenhada na construção de uma nova cidadania para a qual a ciência era peça chave.

Em 13 de março, os astrônomos deixaram Lisboa rumo ao Funchal onde chegaram no dia seguinte, por coincidência o dia em que Albert Einstein (1879-1955) completava 40 anos. Depois de um passeio pela cidade, fizeram-se as despedidas de Davidson e Crommelin, num almoço num restaurante, visto que estes iam regressar ao Anselm, rumo a Belém do Pará, e Eddington e Cottingham permaneciam na Madeira, à espera do vapor para a Ilha do Príncipe.

MADEIRA. IMPRESSÕES DE UMA ILHA ATLÂNTICA Eddington e Cottingham instalaram-se no Hotel Bela Vista (Jones' Bella Vista), gerido por britânicos e com muitos hóspedes dessa nacionalidade, a cerca de 10 minutos a pé do centro da cidade. Para vencerem os declives urbanos acentuados, os viajantes recorreram amiúde a carros de bois (sem rodas, quais trenós) e notaram a predominância de bananeiras, canas de açúcar, vinhas, palmeiras e cactos. Eddington notou também a existência de uma fruta que desconhecia: "as nêsperas, parecidas com alperces mas com sabor próximo do das cerejas” [8].

Eddington sentiu-se muito bem na Madeira. As temperaturas eram elevadas face aquelas a que estava habituado, mas eram do seu agrado; e o clima soalheiro alternava com ventos do deserto e chuvas tropicais. Enquanto Cottingham, já com cinquenta anos e avesso a grandes caminhadas, preferia socializar na cidade, Eddington aproveitou para conhecer a ilha. Subiu ao Terreiro da Luta, ao pico do Areeiro, ao Curral das Freiras, mas também ao Poiso, ao Ribeiro Frio e aos seus balcôes, assinalando altitudes apreciáveis e percorrendo às vezes mais de 25 milhas por caminhada. Apreciou as levadas, mas não gostou das praias rochosas e sujas, ainda que tomasse amiúde banho numa localidade próxima do Funchal, indicada por um jovem britânico em tratamento na Madeira, de quem se tornou amigo e com quem fez várias caminhadas e partidas de xadrez [9].
Quanto à alimentação, Eddington perdeu-se pelas bananas locais, comendo cerca de uma dúzia por dia, classificou a "carne, de cordeiro, vitela e os bifes, como extremamente boa e a melhor que alguma vez provei" [10], e apreciou também o tabaco local.

Os dois viajantes não resistiram aos atrativos do casino, onde iam quase diariamente tomar chá e também, claro, apreciar a emoção de um jogo de roleta, proibido na Madeira mas ainda assim praticado com a complacência da polícia e, no caso deles, também com grande moderação. Entre os seus interlocutores encontravam-se um médico inglês, familiar de Lord Kelvin e, na parte final da estada, um diretor de um jornal local que os ajudou a ultimar a papelada para rumarem a Ilha do Príncipe, divulgando pormenores da expedição no seu periódico [11].

DE FUNCHAL A ILHA DO PRÍNCIPE Eddington e Cottingham ficaram 26 dias no Funchal, partindo no dia 9 de abril para o porto de Santo Antônio, na Ilha do Príncipe, a bordo do vapor Portugal da Companhia Nacional de Navegação, com parada nas ilhas de Cabo Verde, em São Vicente, em 13 de abril, onde se encontrava uma importante estação de cabo submarino telegráfico e, no dia seguinte, 14 de abril, na ilha de Santiago, na cidade da Praia [12].

O vapor Portugal era de dimensão semelhante ao Anselm, também agradável e espaçoso, tal como a cabine em que os astrônomos se instalaram. No entanto, não tinha espreguiçadeiras de aluguel nem instalações para exercício [13].

Cerca de 20 passageiros viajavam em primeira classe, incluindo vários portugueses e sete britânicos, entre os quais se encontravam, para além dos expedicionários, três homens que se dirigiam à estação de cabo de São Vicente, outro que ia dirigir uma refinaria de açúcar e, finalmente, uma jovem missionária, a quem os passageiros dedicavam toda a atenção. A bordo ia também um português, oficial de armada, que falava bem inglês [14]. As atividades de lazer compreendiam jogos variados, entre os quais jogos de tabuleiro (xadrez) e pequenas peças de teatro, pois havia atores a bordo. A comida era boa, incluía carne tenra e sorvetes, mas não particularmente apelativa para o gosto de Eddington, que sofria também com o chá de má qualidade. Mais uma vez, não havia sinais de racionamento, com açúcar e manteiga à vontade e "comendo-se num dia a quantidade de carne da ração semanal" [15].

O tempo esteve quente, o céu límpido com noites de luar até à chegada a São Vicente, uma ilha árida, quente e úmida, com temperaturas na ordem dos $29^{\circ} \mathrm{C}$ à sombra, onde passageiros desceram e outros entraram. Os expedicionários britânicos aproveitaram para visitar a estação de Cabo, nodo de comunicações com o hemisfério sul e ponto estratégico durante a Grande Guerra. A próxima parada foi a cidade da Praia, onde o vapor ficou por poucas horas, seguindo viagem para a Ilha do Príncipe.

Apesar de terem acabado de passar por um dos centros nevrálgicos de comunicações entre a Europa, os Estados Unidos da América e o hemisfério sul (o outro situava-se nos Açores), a verdade 
é que os viajantes se sentiam progressivamente mais afastados de tudo e todos. Poucas ou nenhuma notícia da situação política internacional tinham recebido desde a sua partida do Reino Unido, situação que não tinha sido atenuada pela passagem rápida por Lisboa nem pela estada prolongada no Funchal, onde os jornais publicavam fundamentalmente notícias locais. Dirigiam-se assim para o desconhecido, junto ao equador, e as amarras ao tempo político iam-se esfumaçando, criando enorme ansiedade nos viajantes, que também nada sabiam dos colegas expedicionários dos quais tinham se despedido no Funchal.

PRÍNCIPE. IMPRESSÕES DE UMA ILHA EQUATORIAL Durante o percurso de Cabo Verde a Ilha do Príncipe, o tempo muito nublado nunca permitiu avistar terra, apesar da rota do navio não se afastar mais de 40 milhas do continente. Viram, sim, muitos peixes voadores e bandos de tartarugas, mas nunca baleias ou tubarôes [16]. Ao fim de vários dias, em 23 de abril, os expedicionários chegaram finalmente ao porto de Santo Antônio.

Os portugueses chegaram às ilhas de São Tomé e Príncipe em 1470 , seguindo-se esforços para o seu povoamento, com a introdução da cana de açúcar no século $\mathrm{XV}$, cultura que se encontrava em franco declínio no século XVII devido tanto à concorrência do Brasil como a revoltas locais, o que acabou por reduzir as ilhas a entrepostos de escravos. Unidas administrativamente em 1753, no início do século XX, a colônia de São Tomé e Príncipe tinha-se tornado um expressivo produtor mundial de cacau e de café [17].

As impressões da ilha foram logo positivas, a densa vegetação luxuriante a descer abruptamente até o mar, contrastando agradavelmente com a aridez de Cabo Verde [18]. Ainda a bordo, foram recebidos pelo administrador em exercício da Ilha do Príncipe, Vasconcelos, pelo representante da Sociedade de Agricultura Colonial, Grageira, e pelo presidente da Associação de Plantadores, Jerónimo José Carneiro, um homem jovem estabelecido na ilha há pouco mais de dois anos, cuja família era proprietária, desde 1875, da roça Sundy, uma das maiores plantações do local. Essa recepção formal, incluindo as individualidades que representavam as várias instituições oficiais e roças particulares da ilha não deixava dúvidas sobre a importância concedida pelas autoridades portuguesas aos viajantes e ao propósito da viagem. Tal como referiram "percebemos rapidamente que nos tinha saído a sorte grande" [19].

Apesar dos viajantes não darem informações sobre a população, estima-se que naquela altura não deveria ultrapassar os 6000 habitantes, dos quais provavelmente cerca de $3 \%$ eram portugueses ou europeus e a grande maioria eram trabalhadores das roças [20]. Ainda que a escravatura tivesse sido oficialmente abolida em 1875, a verdade é que o fluxo de trabalhadores vindos de Angola, Cabo Verde e Moçambique para as roças de São Tomé e Príncipe configurou uma situação de trabalhos forçados próxima da escravatura. Essa situação esteve na origem dos conflitos que opuseram o governo português e as autoridades britânicas, nos anos que precederam a implantação da república, pouco mais de uma década antes da viagem dos expedicionários. Com efeito, a empresa familiar Cadbury, um dos maiores compradores do cacau da Ilha do Príncipe, não queria de forma alguma estar envolvida em transaçôes comerciais envolvendo "cacau escravo" [21], dadas as preocupações humanitárias que a sua afiliação religiosa (quakers), a mesma da de Eddington, lhes infundia.

Durante a estada na ilha, o círculo de relacionamentos dos expedicionários foi naturalmente restrito, e compunha-se, para além dos acima referidos, do juiz, do capitão do porto, do tesoureiro, do curador responsável pelo "trabalho importado" [22], de um empregado de escritório de Jerónimo Carneiro assim como de Atalaia, o administrador da roça Sundy, antigo oficial de cavalaria que tinha lutado pela monarquia em 1910 e, depois de passar por Espanha e França, se tinha refugiado ali há quatro anos; e, finalmente, os negros britânicos Lewis e Wright, os únicos dois trabalhadores da Estação de

Cabo. Com excepção destes últimos [23], poucos falavam inglês, não passando as conversas de frases básicas, apoiadas por olhadelas no dicionário. A convivência próxima estabelecida entre Atalaia e Eddington desenrolou-se em francês sumário (o que Cottingham, ainda assim, desconhecia totalmente), mas suficiente para se fazerem entender e até debater temas de interesse comum, principalmente depois do jantar, quando, já na roça Sundy, os trabalhadores vinham discutir com Atalaia os mais variados assuntos.

Na pequena povoação de Santo Antônio, a que passaram logo a chamar cidade, ficaram instalados na residência de Jerónimo Carneiro, uma vivenda nova com uma bela vista para a baía, onde coabitavam pacificamente um macaco, um cão e um gato. Dois dos quatro dias que ficaram na "cidade" foram aproveitados para retemperar forças, passear de lancha ao largo do porto e jogar tênis com o juiz e o curador. As noites foram ocupadas em amena cavaqueira, ao som de música clássica da pianola e gramofone de Jerónimo Carneiro. Dois dos dias foram reservados à escolha do local das observaçóes, no primeiro visitaram de mula as roças Esperança e São Joaquim, no segundo a roça Sundy. Ao chegarem à Sundy, as dúvidas sobre a localização desvaneceram-se.

A casa fica perto da ponta noroeste da ilha, longe das montanhas, num planalto com vista para uma baía situada cerca de 500 metros abaixo. Tínhamos notado esta casa quando nos aproximamos da ilha no vapor. Foi fácil decidir que este era o local mais favorável; e aconteceu que existia um recinto fechado perto da casa que nos servia perfeitamente. Viamo-lo diretamente da janela do nosso quarto. É abrigado a leste por um edifício e aberto em direção ao 


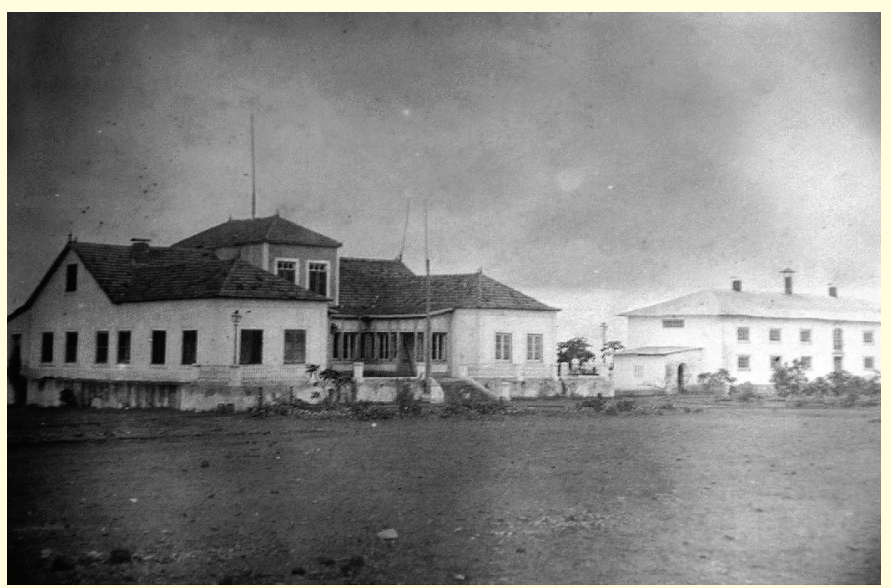

Figura 3. Casa principal da roça Sundy, na traseira da qual foram realizadas as observações. Créditos: herdeiros de Jerónimo José Carneiro

mar, a oeste e a norte - o ideal para o eclipse. Tratamos logo de fazer construir um pedestal para o celóstato e de que a nossa bagagem nos fosse entregue na segunda-feira. [24]

A roça Sundy, tal como todas as roças da ilha, era uma espécie de pequena povoação, organizada em torno da casa principal do administrador, e exibindo capela, escola, hospital, habitações dos trabalhadores que, naquela altura, totalizavam mais de 600, escritórios, armazéns, casa de secagem, oficinas, estábulos e propriedades agrícolas. O espaço escolhido para as observações, na traseira da casa principal onde os astrônomos ficaram instalados, tinha de coordenadas $1^{\circ} 40^{\prime}$ $\mathrm{N}, 29 \mathrm{~m}$ 32s E (723'E) [25]. Os astrônomos mudaram-se para a roça no dia 28 de abril, usando como transporte mulas e carruagem. Chegaram primeiro os astrônomos e só depois as duas toneladas de bagagem que aproveitou os carris da roça, ainda que durante um trecho de cerca de 1 milha fosse carregada por trabalhadores locais.

Foi com a ajuda desses trabalhadores, incluindo carpinteiros e mecânicos, que começaram imediatamente os preparativos da instalação, iniciados com a construção de duas tendas que resistiram "esplendorosamente a um dilúvio" mal foram erigidas, passando assim um exigente teste natural à sua eficácia. A instalação do material (tendas, telescópio, celóstato e mecanismo regulador) prosseguiu mas foi tomada a decisão de não desempacotar o espelho do celóstato para que a umidade não o danificasse. Em carta enviada a Oom, datada de 4 de maio, Eddington refere a ajuda inestimável que lhes estava sendo concedida e acrescenta: "Tudo o que precisamos agora é de um bom dia para o eclipse" [26].

$\mathrm{O}$ adiantado dos trabalhos e o isolamento da Sundy levou os astrônomos a regressarem a Santo Antônio durante uma semana, entre 6 e 13 de maio, para voltarem definitivamente à Sundy ainda a 13 de maio. Nessa última etapa finalizaram a instalação dos instrumentos e procederam a sua afinação e verificação. A partir de 16 de maio foram tiradas fotografias em noites claras, que foram reveladas também durante a noite, um processo lento devido à temperatura demasiado elevada da água.

Depois de chuva copiosa a 9 de maio, a gravana, ou estação fria, instalou-se. Deixou praticamente de chover, mas o céu encobriu-se e as condições meteorológicas pareciam muito menos favoráveis à observação do eclipse do que durante a estação anterior, chuvosa. É bem possível que Eddington começasse a temer pelo resultado da expedição e recordasse o fracasso da observação em Passa Quatro, no Brasil, em 1912, e o de tantos outros astrônomos que tinham visto o esforço hercúleo das suas equipes coroado pelo desapontamento de nada conseguirem observar. Se houve ainda alguns dias desanuviados, os dois dias antes do eclipse foram muito desfavoráveis, os piores até então, e não auguravam nada de bom.

\section{O ECLIPSE DE 29 DE MAIO DE 1919. OBSERVAÇÕES E INVISIBILIDA-} DES Já no barco de regresso à Europa, a descrição que Eddington fez do eclipse, em carta à mãe, é um depoimento claro e detalhado que revela todo o espectro de emoções vividas naqueles pequenos instantes em que tanto trabalho e expectativas convergiam e que as partidas do tempo teimavam em torpedear:

Na manhã do eclipse, o Sr. Carneiro, o curador, o juiz, o Sr. Wright e três médicos juntaram-se a nós. Assim que chegaram, uma tempestade violenta de chuva desabou sobre nós, a mais forte que presenciamos. Era muito incomum naquela época do ano; mas foi favorável ao eclipse, pois ajudou a limpar o céu. A chuva parou por volta do meio-dia (o eclipse era às $2: 15 \mathrm{pm}$ ). Apareceram alguns raios de sol depois da chuva, mas o céu ficou nublado de novo. Por volta da 1:30pm, quando a fase parcial estava avançada, começamos a vislumbrar o sol, à $1: 55 \mathrm{pm}$, podíamos ver o crescente (através das nuvens) quase continuamente, e grandes manchas de céu claro começaram a aparecer. Tivemos que ter fé e acreditar que o nosso programa de fotografias ia ser executado. Não vi o eclipse, estive demasiado ocupado a trocar as placas, exceto por um relance para ter a certeza de que tinha começado, e outro a meio para ver quantas nuvens havia. Tiramos 16 fotografias (das quais 4 ainda não foram reveladas). São todas boas fotos do Sol, mostrando uma proeminência notável; mas as nuvens interferiram muito nas imagens das estrelas. As primeiras 10 fotografias praticamente não mostram estrelas. As últimas 6 mostram algumas imagens que, espero, nos darão o que precisamos; mas é muito decepcionante. Tudo indica que os nossos dispositivos foram bastante satisfatórios e, com um tempo mais desanuviado, deveríamos ter obtido resultados esplêndidos. Dez minutos depois do eclipse, o céu estava limpo, mas pouco depois ficou nublado de novo.

Revelamos 2 fotografias por noite durante 6 noites após o eclipse, e passei os dias a tirar medidas. $\mathrm{O}$ tempo nublado prejudi- 


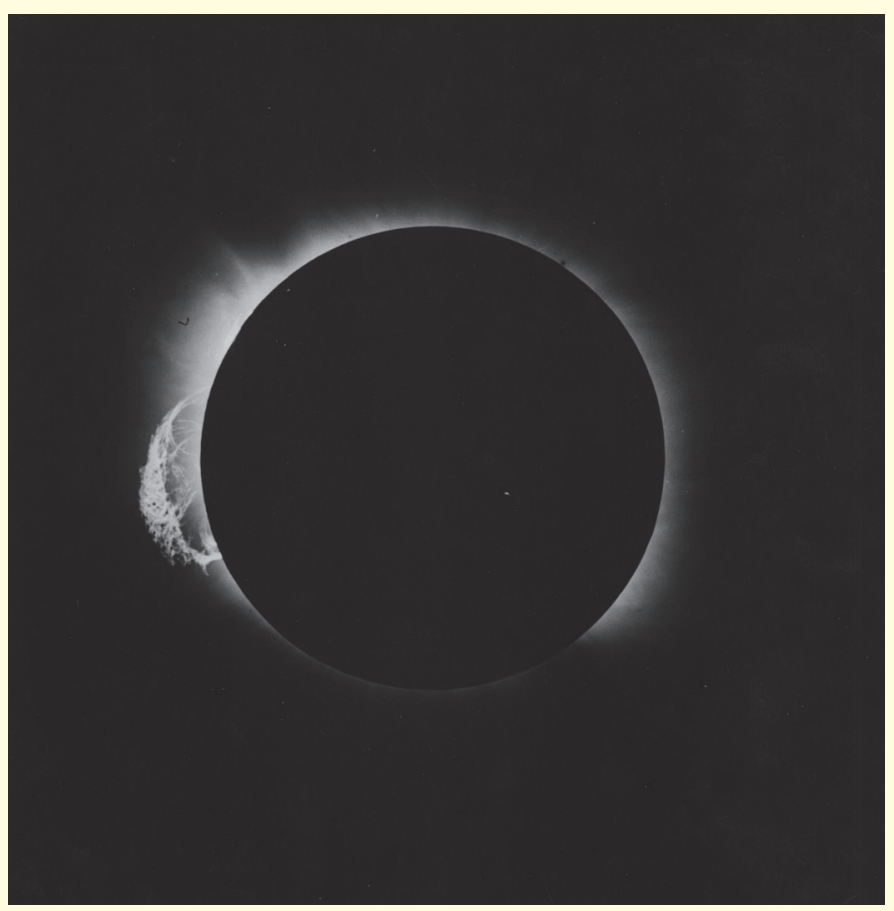

Figura 4. Proeminência solar (orientação leste). Príncipe, 1919. $2 \mathrm{~h} 13 \mathrm{~m} \mathrm{28s} \mathrm{G.M.T.,} \mathrm{exposição} \mathrm{10s} \mathrm{(through} \mathrm{cloud).} \mathrm{Crédito:}$ Arquivo MUHNAC/OAL, PT/MUL/OAL/C/240

cou os meus planos e tive que analisar as medidas de um modo diferente do que pretendia; consequentemente, não consegui fazer nenhum anúncio preliminar do resultado. Mas a placa melhor que medi deu um resultado em concordância com Einstein e acho que consegui uma pequena confirmação de uma segunda placa. [27]

Na verdade, como era de se esperar, há diferenças substanciais entre o relato privado, transcrito acima, e a descrição incluída no artigo conjunto publicado nas Transactions of the Royal Society of London [28], após a apresentação pública, na reunião conjunta da Royal Society of London e da Royal Astronomical Society, ocorrida a 6 de novembro de 1919. Não tanto ao nível das informações fornecidas, que são sensivelmente as mesmas, mas na maior precisão na identificação dos instantes da totalidade e, principalmente, na ausência de referência às emoções sentidas. A descrição pública adjetiva a "excelência" das fotografias e a "notabilidade" da proeminência mas omite a referência à decepção provocada pelo mau tempo, à fé em acreditar na execução do programa e, finalmente, à esperança que os resultados comprovassem a previsão de Einstein.

Mais curioso é notar a forma como Eddington se refere ao eclipse quando, em 1920, no mesmo ano do artigo conjunto, publicou Space, time and gravitation, um livro de divulgação que introduz, de forma não técnica, o público leigo ao formalismo e aparato conceptual da teoria da relatividade. Dois dos capítulos são dedicados às previsões da teoria da relatividade geral, sendo o capítulo "Pesando a luz" consagrado às expediçōes e aos seus resultados. Nele, descreve em termos poéticos o momento mágico da totalidade, de enorme beleza, expectativa e muita azáfama:

A caixa de sombra ocupa toda a nossa atenção. Há um maravilhoso espetáculo acima e, como revelaram as fotos, uma maravilhosa proeminência-chama está posicionada a cem mil milhas acima da superfície do Sol. Não temos tempo nem para uma olhadela. Estamos conscientes apenas da estranha meia-luz da paisagem e do silêncio da natureza, interrompidos pelas chamadas dos observadores e a batida do metrônomo, que conta os 302 segundos de totalidade. [29]

Em termos do conteúdo dos relatos escritos identifica-se, assim, uma gradação decrescente de emoções, da riqueza da comunicação privada, que póe a nu os sentimentos do astrônomo, ao texto de divulgação, que descreve com comoção a paisagem e o ambiente mas omite referências ao sentir do astrônomo e, finalmente, à publicação científica, factual e mais detalhada nos pormenores e informações técnicas.

Note-se ainda que no artigo científico se omite a referência às testemunhas locais que acompanharam o trabalho dos expedicionários, enumeradas na carta à mãe (os "Sr. Carneiro, o curador, o juiz, o Sr. Wright e três médicos juntaram-se a nós") e intuídas pelo leitor atento do livro de divulgação, através da menção aos "observadores" que faziam o chamamento crucial à mudança de chapas nos instantes devidos. Assim, apesar da sua invisibilidade, dois tipos de atores locais participaram diretamente nas experiências: os trabalhadores, que forneceram a mão de obra para a construção de suportes para os instrumentos ou estruturas de proteção de toda a aparelhagem, e os membros da elite local que participaram nas observaçôes da totalidade. Estes vieram juntar-se aos astrônomos, autoridades e individualidades nacionais e coloniais, que asseguraram o sucesso da viagem e da permanência dos expedicionários em Funchal e na Ilha do Príncipe.

Os dias que se seguiram ao eclipse foram ocupados na revelação e medição de 12 das 16 chapas tiradas. Na Ilha do Príncipe, como em Sobral, recorreram à ajuda local, neste caso ao gelo fornecido por Grageira para assegurar condições de temperatura adequadas da revelação [30]. Ainda assim, quatro das chapas não puderam ser reveladas dada a composição do seu material ser inadequada às condições locais [31]. Entretanto, foi tomada a decisão de não ficarem na ilha para obter as chapas extras de comparação, pois um "braço de ferro" entre o governo português e a companhia de navegação quanto ao preço dos bilhetes anunciava uma greve sem fim à vista. Optaram por recorrer às tiradas no início do ano em Oxford, em condições razoáveis mas não ideais, para funcionarem como chapas de comparação [32].

Os dias restantes até a partida foram ocupados numa caçada de macacos, abundantes na ilha a ponto de haver trabalhadores das 
roças destacados propositadamente para os afastarem das árvores de cacau; num passeio a uma das dependências da Sundy onde se plantava uma variedade muito especial de cacau: "era uma visão linda ver as grandes vagens douradas em tal número que a floresta parecia iluminada por lanternas chinesas" [33]; numa visita à Lapa, propriedade da Sociedade Agrícola Colonial, onde nadaram com cautela por causa dos tubarôes e onde comeram peixe na praia, uma faixa de areia muito branca que se estendia entre os coqueiros e o mar; e numa visita à pequena ilha Bom Bom e às ruínas da habitação apalaçada de uma conhecida negociante de escravos.

REGRESSO E ANÚNCIO Com ajuda oficial, os astrônomos conseguiram lugar no navio superlotado S.S. Zaire, partindo em 12 de junho de Santo Antônio, na companhia de Jerónimo Carneiro. Partilharam cabine com um tripulante português, reencontraram a jovem missionária com quem tinham feito a viagem para a Ilha do Príncipe e conheceram uma outra missionária quaker.

A viagem de regresso, pior e mais lenta que a da ida, foi amenizada por um telegrama de Dyson que afirmava: "a equipe do Brasil foi bem sucedida" [34]. Na verdade, o telegrama enviado por Crommelin a Dyson dizia "Eclipse esplêndido", o que, de acordo com o código pré-estabelecido, significava um eclipse perfeito, enquanto que o de Eddington anunciava "Através de nuvens. Esperançoso" [35], quebrando o código, mas mantendo o otimismo, apesar da decepção [36].

Passaram pela cidade da Praia no dia 20 de junho e chegaram a Lisboa em data incerta, entre 30 de junho e 2 de julho. De Lisboa partiram a bordo de um vapor também superlotado da Royal Mail Steam Packet Line, chegando a Liverpool em 14 de julho.

O verão foi passado no trabalho de análise e redução dos dados das fotografias tiradas na Ilha do Príncipe e em Sobral, ao mesmo tempo que Einstein se sentia cada vez mais apreensivo na ausência de notícias. A 22 de setembro, Einstein recebeu a indicação de que os resultados apontavam no sentido das suas previsões [37].

Conhecem-se os detalhes da apresentação pública, em 6 de novembro, na célebre sessão conjunta referida acima [38], que se revestiu de enorme pompa e circunstância. Os resultados obtidos eram compatíveis com as previsōes de Einstein. A análise do que se passou nessa reunião e o seu impacto no Reino Unido, na Alemanha, no Brasil, em Portugal e no resto do mundo, não podem ser abordados neste artigo. Basta referir que as suas repercussões, tanto científicas como populares, incluíram discussões acesas e, ao mesmo tempo, catapultaram Einstein para o estrelato científico, eclipsando, no processo, os próprios expedicionários.

À LAIA DE CONCLUSÃO Não quero terminar sem ponderar as razões da ausência de referências, nas cartas e publicações de Eddington, ao trabalho nas roças e ao "cacau escravo", tanto mais que, à primeira vista, as suas convicções e práticas religiosas apontariam em sentido contrário. Contudo, numa segunda leitura, a consideração pelos valores éticos da educação de Eddington, ocorrida numa sociedade de estrutura marcadamente classista, assim como as expectativas comportamentais nas relaçōes entre anfitriāo e convidado na roça Sundy, permitem entender a ausência desse assunto, tanto nos relatos públicos como nos privados.

A esses aspectos acrescente-se a visão que os cientistas foram arquitetando, pelo menos desde o século XVII, da ciência, dos cientistas e do seu métier, que os colocava nos antípodas da sociedade real em que existiam. Essa foi, aliás, a visão que subjaz à estratégia desenvolvida apaixonadamente por Eddington no pós-expedição. Empenhou-se em apresentá-la ao mundo como instância por excelência de internacionalismo científico, tanto mais cativante quanto tinha decorrido numa situação política de conflito bélico entre o país dos astrônomos que mediram o encurvamento e o do físico que o previu. Apesar de atraente, essa narrativa é uma construção de uma comunidade (a dos cientistas), empenhada em afirmar a sua importância e estatuto socioprofissionais e hegemonia epistemológica. Muitas vezes, no passado como no presente, e o caso do eclipse de 1919 oferece um exemplo significativo nesse sentido, construção narrativa e prática científica entram em conflito, por vezes de forma dramática. Tendo estes aspectos em mente a invisibilidade do cacau escravo deixa, mais uma vez, de ser surpreendente, ainda que se mantenha incômoda. É antes, sim, um sinal dos tempos. É antes, sim, reflexo das construçôes narrativas, das mitologias, de uma comunidade.

Ainda que parciais e de formatos e extensão diversos, uns de cariz privado e outros públicos, os relatos que Eddington deixou da sua aventura entrelaçam impressôes pessoais, comentários subjetivos e considerações científicas. Analisados em conjunto, permitem reconstituir as vivências da expedição e evidenciar as suas múltiplas facetas, científicas, sociais e políticas. Reveladores, tanto pelo que mencionam como pelo que omitem, esses relatos são uma componente essencial para a reconstrução da história do eclipse de 1919, rumo a uma história global.

Ana Simões éprofessora catedrática do Centro Interuniversitário de História das Ciências e Tecnologia, Faculdade de Ciências, Universidade de Lisboa.

\section{AGRADECIMENTOS}

Agradeço o apoio dos Master and Fellows of Trinity College, Cambridge, pelo uso da correspondência de Eddington, e da Fundação para a Ciência e Tecnologia, Portugal, no âmbito do projecto UID/HIS/00286/2019.

\section{NOTAS E REFERÊNCIAS}

1. Crelinsten, J. Einstein's jury. The race to test relativity. Princeton: Pricenton University Press, 2006; M. Stanley, Practical mystic: religion, science and A.S. Eddington. Chicago: Chicago University Press, 2007; Mota, E.,Crawford, P., Simões, A. "Einstein in Portugal: Eddington's 
expedition to Príncipe and the reactions of portuguese astronomers (1917-1925). In: British Journal for the History of Science, 42, pp. 245-73, 2009; Simões, A. "O eclipse de 29 de maio de 1919 e a teoria da relatividade. Um encontro improvável". In: Gazeta de Física, 42, pp. 4-7, 2019.

2. Pang, A. S. K. Empire and the Sun. Victorian solar eclipse expeditions. Stanford: Stanford University Press, 2002.

2. Crommelin, A. C. C. "The eclipse expedition to Sobral". In: The Observatory, 42, pp. 368-71, p. 368, 1919.

3. Trinity College Library, Cambridge. Correspondência de Eddington (TCL: EDDN A4/2). 15 de março de 1919. Neste artigo baseio-me nas cartas de Eddington à mãe Sarah Ann Eddington e à irmã Winnifred Eddington. No que se segue e no que se refere às cartas à mãe indicarei, por simplicidade, apenas a data da carta.

4. Crommelin, (ref. n.3), p. 368; TCL: EDDN A4/2. 15 de março de 1919; Arquivo MUHNAC/OAL (Arquivo do Observatório Astronómico de Lisboa): Bilhete de F. Oom.

5. TCL: EDDN A4/2. 3 de setembro de 1912.

6. Carolino, L. M.; Simões, A. "The eclipse, the astronomer and his audience: Frederico Oom and the total solar eclipse of 28 may 1900 in Portugal". In: Annals of Science, 69, pp. 223-226, 2012. Carolino, L. M.; Simões, A. "Frederico Oom e a promoção da astronomia em Portugal". In: Gazeta de Física, 42, pp.17-20, 2019.

7. TCL: EDDN A4/2. 15 de março de 1919.

8. TCL: EDDN A4/2. 27 de março, 6 e 13 de abril de 1919.

9. TCL: EDDN A4/2. 27 de março de 1919.

10. TCL: EDDN A4/2.13 de abril de 1919.

11. TCL: EDDN A4/2. 20 de abril de 1919.

12. TCL: EDDN A4/2. 5 de maio de 1919.

13. TCL: EDDN A4/2.20 de abril de 1919.

14. TCL: EDDN A4/2. Carta de Eddington a Winnifred Eddington, 5 de maio de 1919.

15. TCL: EDDN A4/2. 29 de abril - 2 de maio de 1919.

16. Nascimento, A. "Poderes e quotidianos nas roças de S. Tomé e Príncipe", tese de doutoramento, 2002; Histórias da Ilha do Príncipe. Oeiras: Município de Oeiras, 2011; Pape, D.; Andrade, R. R. As roças de São Tomé e Príncipe. Lisboa: Tinta da China, 2013.

17. TCL: EDDN A4/2. 29 de abril - 2 de maio de 1919.

18. TCL: EDDN A4/2. 29 de abril - 2 de maio de 1919.

19. Não é fácil encontrar dados sistemáticos sobre a população da ilha, pelo que é necessário cruzar fontes, nem sempre fáceis de localizar, sendo quaisquer estimativas sempre provisórias. Por exemplo, em Seibert, G. "Patrimônio edificado de São Tomé e Príncipe. A roça Sundy". In: China e países Iusófonos - patrimônio construído. Macau: Instituto Internacional de Macau, pp.394-415, 2016, afirma-se que "em 1908 havia 3300 serviçais na Ilha do Príncipe, a maioria da população da ilha tinha descido para 3830, sendo 150 brancos e 350 ilhéus" (p.407) (e a população da Ilha do Príncipe não devia ultrapassar 6\% da de São Tomé). De acordo com o Boletim Geral das Colónias, Vol43 (S.Tomé e Príncipe), Portugal, Agência Geral das Colónias, 1929, a po- pulação do Príncipe era de 5311 habitantes em 1914 e 6903 em 1921. Agradeço a Duarte Pape a indicação desta última fonte que me permitiu fazer uma melhor estimativa da população do Príncipe.

20. Jerónimo, M. B. The 'civilizing mission' of portuguese colonialism, 1870-1930. New York: Palgrave Mcmillan, 2015; Gisa Weszkalnys, "Principe eclipsed. Commemorating the confirmation of Einstein's theory of general relativity". In: Anthropology Today 25, pp. 8-12, 2009.

21. TCL: EDDN A4/2. 29 de abril -2 de maio de 1919.

22. A existência de trabalhos ingleses na Estação de Cabo tinha sido referida por Oom na correspondência com Eddington.

23. TCL: EDDN A4/2. 29 de abril -2 de maio de 1919.

24. Dyson, F. W.; Eddington, A.; Davidson, C. "A determination of the deflection of light by the sun's gravitational field, from observations made at the total solar eclipse of may 29,1919". In: Royal Society of London. Philosophical Transactions A 220 pp. 291-333, p.313, 1920. Traduzido em: Nunes dos Santos, A. M.; Auretta, C. (coords.). Eddington e Einstein. Lisboa: Gradiva, 1992.

25. Arquivo MUHNAC/OAL. PT/MUL/OAL/C/240.

26. TCL: EDDN A4/2. 21 de junho e 2 de julho de 1919.

27. Dyson et al., (ref. n.25).

28. Eddington, A. S. Space, time and gravitation: an outline of the general relativity theory. New York: Harper Row, pp.110-22, p.115, 1959, $1^{\mathrm{a}}$ edição 1920.

29. Dyson et al., (ref. n.25). p.316.

30. Eddington, (ref. n.29), p. 116.

31. Dyson et al., (ref. n.25). p.314, 317.

32. TCL: EDDN A4/2. 21 de junho de 1919.

33. TCL: EDDN A4/2. 21 de junho de 1919.

34. The Observatory 42 (540), p.256, 1919.

35. The Observatory, 42 (541), pp. 261-272, pp. 261-2, 1919. Reunião de 13 de junho de 1919.

36. Fölsing, A. Albert Einstein. pp.433-52. London: Penguin, 1998.

37. "Joint eclipse meeting of the Royal Society and the Royal Astronomical Society". In: The Observatory 42, pp. 389-98, 1919. 